\title{
Low Velocity Airdrop Tests of an X-38 Backup Parachute Design
}

\author{
Jenny M. Stein ${ }^{*}$ and Ricardo A. Machin ${ }^{\dagger}$ \\ NASA Johnson Space Center, Houston, Texas, 77059 \\ Dean F. Wolf $f^{\ddagger}$ \\ Albuquerque, New Mexico, 87111 \\ and \\ F. David Hillebrandt ${ }^{\S}$ \\ United Space Alliance, Kennedy Space Center, Florida, 32815
}

\begin{abstract}
The NASA Johnson Space Center's X-38 program designed a new backup parachute system to recover the 25,000 lb X-38 prototype for the Crew Return Vehicle spacecraft. Due to weight and cost constraints, the main backup parachute design incorporated rapid and low cost fabrication techniques using off-the-shelf materials. Near the vent, the canopy was constructed of continuous ribbons, to provide more damage tolerance. The remainder of the canopy was a constructed with a continuous ringslot design. After cancellation of the $X-38$ program, the parachute design was resized, built, and drop tested for Natick Soldiers Center's Low Velocity Air Drop (LVAD) program to deliver cargo loads up to 22,000 lbs from altitudes as low as $\mathbf{5 0 0}$ feet above the ground. Drop tests results showed that the 500foot LVAD parachute deployment conditions cause severe skirt inversion and inflation problems for large parachutes. The bag strip occurred at a high angle of attack, causing skirt inversion before the parachute could inflate. The addition of a short reefing line prevented the skirt inversion. Using a lower porosity in the vent area, than is normally used in large parachutes, improved inflation. The drop testing demonstrated that the parachute design could be refined to meet the requirements for the 500-foot LVAD mission.
\end{abstract}

\section{Nomenclature}

$\begin{array}{ll}A G L & =\text { above ground level } \\ C G & =\text { center of gravity } \\ C R V & =\text { crew return vehicle } \\ D T V & =\text { drogue test vehicle } \\ I S S & =\text { international space station } \\ K S C & =\text { Kennedy Space Center } \\ l b & =\text { pound (mass) } \\ l b / i n & =\text { pounds per inch } \\ L V A D & =\text { low velocity air drop } \\ M S L & =\text { mean sea level } \\ U S A & =\text { United Space Alliance } \\ Y P G & =\text { Yuma Proving Ground }\end{array}$

\footnotetext{
* Parachute Lead, Exploration Systems Engineering Office/EX3, AIAA Associate Fellow.

${ }^{\dagger}$ Project Lead, Aeroscience and Flight Mechanics Division/EG, AIAA Member.

$\ddagger$ Consultant, AIAA Associate Fellow.

${ }^{\S}$ Parachute Engineer, Parachute Refurbishment Facility, AIAA Member.
} 


\section{Introduction}

The mission of the X-38 spacecraft was to provide an emergency escape and crew return vehicle for the International Space Station (ISS). The spacecraft was a lifting-body configuration, which used a large steerable inflatable parafoil to flare and softly land the vehicle. The weight of the X-38 spacecraft increased during its development test program because the requirements for ISS crew capacity increased. An initial X-38 configuration with a capacity for 4 crewmembers had a weight of $15,000 \mathrm{lb}$. When the required capacity increased to 7 crewmembers, the vehicle weight increased to $25,000 \mathrm{lb}$.

As a backup to the parafoil system, a backup parachute system using a cluster of three round parachutes was designed to recover the $25,000 \mathrm{lb}$ spacecraft. Due to spacecraft weight and program cost constraints, the main parachute was designed using rapid and low cost fabrication techniques and off-the-shelf materials. The parachute was designed but not built due to the cancellation of the X-38 program. After cancellation of the program, NASA discussed the possible application of this design for Natick Soldiers Center's Low Velocity Airdrop (LVAD) program to deliver cargo loads up to 22,000 lbs from altitudes as low as 500 feet above the ground. The low cost construction and design features of the X-38 design appeared to make it applicable to the 500 foot LVAD mission. Therefore, a cooperative effort between NASA and Natick was put into place to test the X-38 backup parachute design in the LVAD deployment mode. NASA designed and fabricated the parachutes, and Natick provided some support for the drop tests. This paper describes the parachute design, drop tests results, failure analysis, corrective modifications, and recommendations for parachute designs to meet the 500 foot LVAD mission requirements.

\section{X-38 Backup Main Parachute}

\section{A. System Requirements}

The X-38 program was building a prototype called V-201, shown in Fig. 1. For the orbital test flight of V-201, the Space Shuttle was going to carry the vehicle into orbit and release it into space. After a short time in orbit, V-201 was going to de-orbit and land on earth. Initially, the backup parachute system base-lined for V-201 was the one flown on all eight of the atmospheric test flights conducted at Edwards Air Force Base ${ }^{1}$. However, V-201 weighed 25,000 $\mathrm{lbs}$ and the atmospheric test vehicle was only $15,000 \mathrm{lbs}$. The backup parachute system had sufficient margin to handle the drogue high dynamic pressure deployment conditions of $430 \mathrm{psf}$, but it was sized to land a $15,000 \mathrm{lb}$ vehicle at 35 feet per second. With its higher weight, V-201 would land with a vertical velocity of 46 feet per second, resulting in damage to the structure.

To reduce the landing vertical velocity to 30

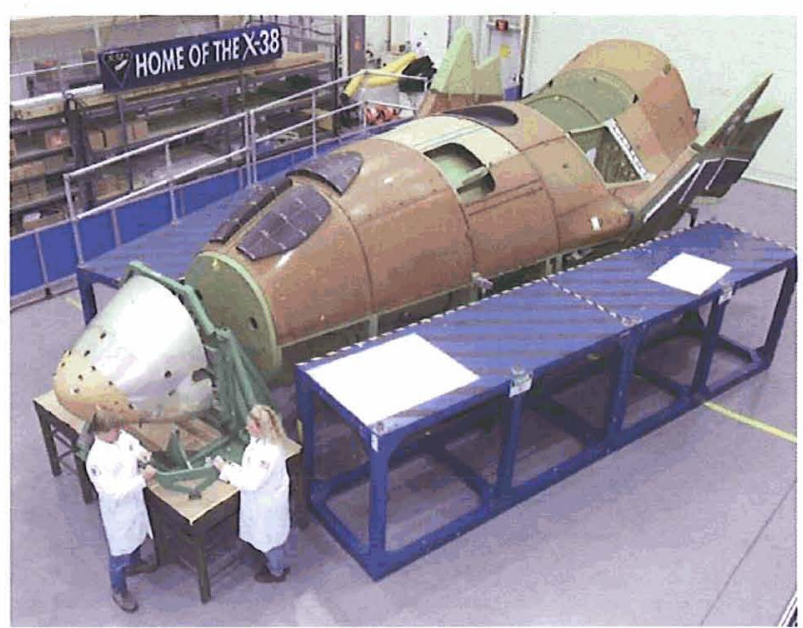

Figure 1: $\mathrm{X}-38 \mathrm{~V}-201$ in fabrication

feet per second, alternative parachute systems were investigated. In this investigation, two challenges had to be met. The first challenge was that the alternative system could not exceed the weight and volume of the base-lined parachute system; the second challenge was that the cost had to be within cost constraints of the program. A backup parachute system was designed to meet those challenges. The pilot and mortar were not changed, but a new drogue and main parachute were required. This paper will concentrate upon the main parachute design.

\section{B. Parachute Design}

The design methodology used was the same as used for round parachutes deployed by drogue parachutes. This methodology consists of selecting a canopy type, size and number of parachutes that satisfies a performance requirement, such as landing rate of descent. Loads during deployment are controlled using reefed stages. Detailed internal loads are calculated to allow materials to be selected that provide structural integrity. Applying the appropriate design factors, the safety margins are calculated. This methodology has been very effective for many high performance and highly loaded parachutes that also had to be very efficient and lightweight, such as the parachutes used in the X-38 program. These parachute systems use a drogue parachute to slow and stabilize the load 
and set up the deployment conditions for main parachute deployment. An important feature of this type of main parachute deployment is that these parachutes are deployed at small angles of attack and have reefed stages. The significance of this feature was discovered during the drop test program for the 500 -foot LVAD program and will be discussed later in this paper.

Following the above design methodology, the X-38 program selected a 120 -foot diameter continuous ribbon/continuous panel ringslot parachute for the backup main parachute. Using a cluster of three main parachutes, the V201 landing velocity was lowered to 30 feet per second. The slotted canopy design would provide both drag and stability. The top portion of the canopy was a continuous ribbon design as was implemented on the X-38 drogue parachutes. A continuous ribbon design has high structural efficiency due to the fewer number of sewn joints. A vent hoop ${ }^{2}$ was utilized instead of vent lines to minimize vent damage and entanglement. The remainder of the parachute was a continuous ringslot design, with one splice. The ring width was selected to eliminate the need for mini radials and verticals, and the rings were constructed from strips of hot-cut coated nylon fabric to save weight and to reduce manufacturing complexity. Rip-stops were also incorporated into the design to limit damage propagation. Because the X-38 program was a prototype for a human-rated spacecraft, damage prevention and control was a priority in parachute design. The total design factor was 2.5 , and the design load of the parachute was $30,000 \mathrm{lb}$ per parachute.

\section{Drop Testing}

Prior to the cancellation of the X-38 project, drop testing was conducted to evaluate the use of hot-cut coated nylon fabric for the parachute rings to further reduce manufacturing costs. Results indicated that the hot-cut edges did not hold up under a high dynamic pressure flutter environment. A 16-ft subscale version of the parachute was built for these tests. The normal ribbons were replaced in selected areas with ribbons made form hot-cut fabric strips. A lightweight bomb-type vehicle, referred to as a drogue test vehicle (DTV), was dropped from a Huey helicopter and allowed to free-fall to achieve the required dynamic pressure at parachute deployment. United Space Alliance (USA) packed the parachutes, and Pioneer Aerospace rigged the DTV and provided field support. Two drop tests, P2D21 and P2D22, were conducted. For each test, the DTV was ballasted to 1,000 lbs and dropped from 10,000 ft MSL. The parachute was deployed at a dynamic pressure of 76 psf. Although most of the hot-cut ribbons survived with no damage, some ribbons showed fraying damage adjacent to radials. The hot-cut fabric ring method of fabricating the continuous panel ringslot parachutes was rejected based upon the test data.

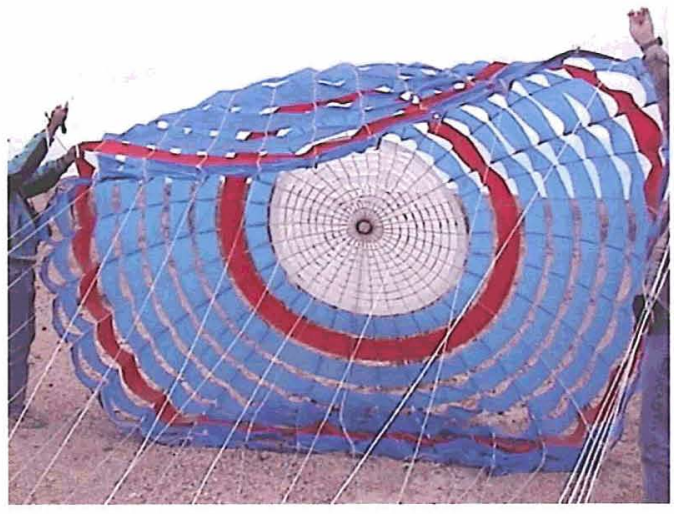

Figure 2. Post-drop inspection of subscale parachute

\section{Low Velocity Airdrop (LVAD) Parachute}

\section{System Requirements}

An Operational Requirements Document was released by Natick for a low velocity airdrop system capable of air dropping platforms from a C-130 or C-17 traveling at airspeeds from 130 to 150 knots indicated airspeed from 500 feet above ground level (AGL). The threshold rigged platform weight was 2,520 to 15,500 lbs with an objective of $22,000 \mathrm{lbs}$. The target landing vertical velocity was 28.5 feet per second or less on a 100 degrees Fahrenheit day at $5,000 \mathrm{ft}$ MSL.

\section{E. Parachute Design}

The low cost construction and design features of the X-38 backup main parachute design appeared to make it applicable to the 500 foot LVAD mission. Therefore, a cooperative effort between NASA and the Natick Soldiers Center was put into place to test the X-38 backup parachute design at the LVAD deployment conditions.

The only design feature that was changed was that the rings for the ringslot portion of the parachute would be sewn instead of hot cut. This decision was based upon the drop testing discussed above. Maintaining a minimum design factor of 2.5 , the resulting design load for a single parachute was $27,100 \mathrm{lbs}$ and $38,000 \mathrm{lbs}$ for a cluster of 
three parachutes. Parachute load and dynamics models were used in the design process. A CANO ${ }^{3}$ internal loads analysis was used in the selection of the strength of the materials for the parachutes.

The size of the parachute was adjusted to deliver a total rigged load of $15,500 \mathrm{lbs}$ that would land at 28.5 foot per second. This resulted in the selection of a cluster of three 105-foot diameter parachutes. The parachute coefficient of drag was 0.625 and the drag area was 5,412 square feet. The suspension lines were made of $1,000 \mathrm{lb}$ Spectra and had a suspension line to parachute diameter ratio of 1.0.

A gore sketch is shown in Fig. 3. The vent hoop consisted of two hoops. Each hoop was two plies of $6,500 \mathrm{lb}$ Kevlar braided cord. The ribbon portion at the top of the canopy was constructed with $2,500 \mathrm{lb}$ nylon webbing at the vent and $750 \mathrm{lb}$ nylon ribbons below the vent. The rings of the ringslot portion of the canopy were constructed of $42 \mathrm{lb} / \mathrm{in}$ nylon fabric. A total porosity was selected to balance conflicting design requirements of drag, stability, inflation time, loads, and weight. Whereas, low porosity provides high drag and faster inflation, it also results in poorer stability and higher inflation loads. Parachute weight is proportional to design load. For the LVAD deployment conditions, the speed of inflation and stability were considered driver factors due to the low altitude extraction and limited time to touchdown. Because parachutes with a total porosity less than 15 percent are known to exhibit poor stability, the team selected 15 percent to stay within the experience base for stability.

For the initial drops, a modified X-38 drogue deployment bag was used. However, this was replaced with a new deployment bag after extensive deployment problems and damage were experienced during the first two drop tests. The new bag was modeled after the G-11 deployment bag and was designed to withstand a $90 \mathrm{~g}$ acceleration at the beginning of deployment. The margins of safety were calculated using a 2.5 design factor.

The parachutes and deployment bag were fabricated by USA at the Parachute Refurbishment Facility located at NASA's Kennedy Space Center (KSC).

\section{F. Drop Test Program Overview}

The drop test program consisted of five Low Velocity Air Drop (LVAD) tests using a single parachute and one LVAD test using a cluster of three parachutes. These drop tests were conducted at the U.S. Army Yuma Proving Ground (YPG) in Yuma, Arizona. The parachutes were packed by USA and rigged to the platform by the YPG riggers. These LVAD tests were performed using a standard weight tub and platform combination with the parachute rigged to the top of the weight tub as shown in Fig. 2 (don't know if I have a good picture of this. Do you?).

The single parachute drop tests were planned to evaluate deployment, inflation, and load characteristics of a single parachute. As with any new parachute, single parachute drop testing also is needed to develop the packing procedures. The cluster drop was intended to demonstrate the performance of the parachutes in a cluster. The test articles for the single and cluster parachute tests weighed 5,000 and 15,500 pounds, respectively. The drop altitudes were higher than 500 feet AGL to provide time to evaluate the parachute full open performance. The drop altitude was 5,000 feet AGL for the first drop and 1,200 feet AGL for the remaining drops, including the cluster drop. Standard range services used included Kineto Tracking Mounts for tracking data, ground-to-air and on board video, still photography, and parachute and load post-drop recovery.

The testing utilized the drop test process developed in the X-38 program $^{1,4}$. Part of that process included the used of the Decelerator System Simulation ${ }^{5}$, which is a model used to predict drogue sling loads during inflation; disreef event timing, dynamics and inflation loads; and over-rotation during payload extraction from cargo aircraft. The over-rotation simulation was developed to bound the acceptable test article center of gravity (CG) for the platform configuration. If the CG is too far aft, the platform will over-rotate immediately upon extraction from the aircraft and can result in the load being upside down, causing the riser to strike the load or become entangled with the load. Damage to the riser could lead to riser failure and loss of the load. Due to this concern, the X-38 developed the weight and balance for each load to ensure that the over-rotation was 120 degrees or less. The assembly of the load 
was modeled using a spreadsheet identifying the location of the components and tub weights. The weight and CG of the load was verified prior to being loaded onto the C-130. All platforms were within the CG limits for all drop tests.

A subset of the instrumentation used during the X-38 program $^{1}$ was also used in the single parachute 500 -foot LVAD tests. An onboard data acquisition system consisted of a GMH Engineering Data Brick that collects and stores data. The recorded data included a motion pack, which is a tria-axial accelerometer and rate gyro package, a pitch attitude sensor, a 25g Crossbow 3-axis accelerometer, a 50g Crossbow 3-axis accelerometer, and sling strain links. Other standalone instrumentation included an IST impact recorder and Tension Measuring System (TMS) ${ }^{6}$ load measuring and recording devices. The TMS units were programmed and installed on the deployment line and riser. Each unit has a pull pin. A lanyard is attached to the pull pin, and the lanyard is attached to the component for which the load is to be measured. As the deployment line loads up or the riser is extracted out of the deployment bag, the lanyards pull the pins from the units, thus arming the units. In this way, the opening loads and full open steady state loads are measured.

The impact recorder was hard-mounted to the test tub and is a self-contained 50g tri-axial accelerometer package and data system that records discrete events triggered when any accelerometer senses an acceleration that exceeds a user programmed threshold.

\section{G. Drop Test Results}

The first five drops were single parachute drop tests, and on three of the five drops, the parachute did not inflate to full open. On the first three drop tests, the parachute suffered extensive deployment-related damage, skirt inversion, and skirt blockage. By the fourth drop test, changes were incorporated to stop the skirt inversion and damage, however, inflation to full open was still a problem. The sixth drop test was a cluster of three parachutes. Inflation to full open was achieved on all three parachutes, although the inflation was more sluggish than desired. A summary of the drop test results is given below.

\section{Drop Test 1 -October 21, 2002}

The parachute suffered line entanglement and line dump, minor skirt inversion, and skirt damage and failed to inflate to full open. The line entanglement occurred at the suspension line to dispersion bridle joint and was attributed to the heavy metal links used at that juncture. The corrective action was to replace the metal links with fabric links.

Line dump was the result of undersizing the strength of the stowage ties to handle the high snatch acceleration loads for the metal links as the extraction parachute deployed the main parachute. The riser and suspension line stowage ties were changed to a stronger strength material. Different parachute packing techniques were also investigated. At this point, the types of problems that the team was working were those typically encountered during the process of developing a new parachute and its packing procedure.

The failure to inflate the parachutes and the presence of skirt damage presented the greatest puzzles to be solved. Analysis of the suspension line entanglement revealed the effective length of the suspension lines was about 60 feet instead of 105 feet, which was not sufficient to prevent inflation. There was a suspicion that the porosity was higher during inflation due to the change in the canopy slot openings due to the lack of mini radials or other slot shape control devices. The damage at the skirt band and failure to inflate was not understood at that time.

\section{Drop Test 2 -October 24,2002}

The changes incorporated after drop test 1 solved the suspension line entanglement and dump problems. However, a severe skirt inversion occurred, shown at the lower part of the parachute skirt in Fig. 4. This inversion resulted in a "Mae West" inflation of canopy material outside of the skirt band, as shown in Fig. 5.

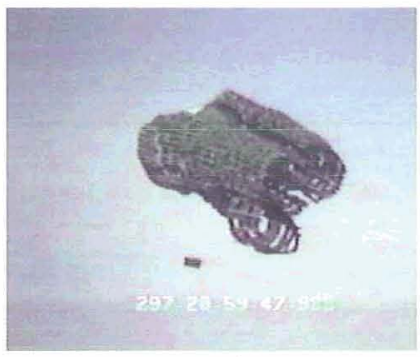

Figure 4. Skirt inversion in test 2

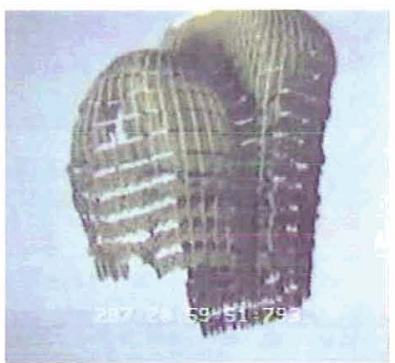

Figure 5. "Mae West" inflation in test 2 
The parachute was heavily damaged, but the ripstops functioned properly and limited the extent of damage. The inversion cleared, and the parachute inflated to full open. The skirt band and radial joint were redesigned to make it more failure tolerant. But the cause of the skirt inversion was still unknown. At that time, the problem was attributed to the deployment bag design, which was a modified X-38 drogue deployment bag, in that the bag lacked the appropriate canopy compartment closure configuration. A new deployment bag was built based upon the G-11 deployment bag.

High porosity during inflation due to the opening of the slots was still considered a potential factor in the inflation problems. To address this issue, tabs were added in the wide slots of the canopy to better control shape and thus porosity, during inflation.

\section{Drop Test 3 - November 19, 2002}

Again, the parachute had a skirt inversion, but the inversion was not as large and did not clear, resulting in failure of the parachute to inflate to full open. The persistence of the skirt inversion and inflation problem indicated that there was an unidentified failure mechanism, and as a result, a more detailed analysis was conducted using the drop test videos. A frame-by frame analysis of the videos from the first three drop tests revealed that skirt inversions had occurred on all three tests in varying degrees. At this point it was concluded that the skirt inversions were not only causing the parachute damage, but were preventing the parachute from inflating. A short reefing line was installed and cut with a short time delay cutter to prevent the skirt inversions. The reasons for the short reefing line and the resulting parachute changes identified and tested on the fourth, fifth and sixth drop tests are discussed in the section discussing the failure analysis.

\section{Drop Test 4-March 25, 2003}

There was no skirt inversion, however, the parachute failed to inflate to full open. A very large infold, as shown in Fig. 6, was observed on the windward side of the canopy. The infold persisted throughout the flight and prevented enough air from flowing into the canopy to cause inflation. It was now clear that there were two failure modes, both caused by the same phenomenon. A cross-flow at the parachute skirt during deployment closed the skirt opening and, if not controlled, caused an inversion. An attempt to improve the parachute inflation characteristics was made by lining the vent area with low porosity cloth.

\section{Drop Test 5-May 14, 2003}

There was no skirt inversion or parachute damage. The same large infold occurred on the windward side of the canopy. However, the low porosity vent area of the canopy did not allow the small inflow of air at the parachute skirt to escape, and the parachute sluggishly inflated to full open. More details on the design changes are discussed in the following section.

\section{Drop Test 6-May 16, 2003}

This was the only cluster drop test conducted. All three parachutes were modified to include the low porosity vent area and a short reefing line. None of the parachutes had a skirt inversion, and all three parachutes inflated to full open.

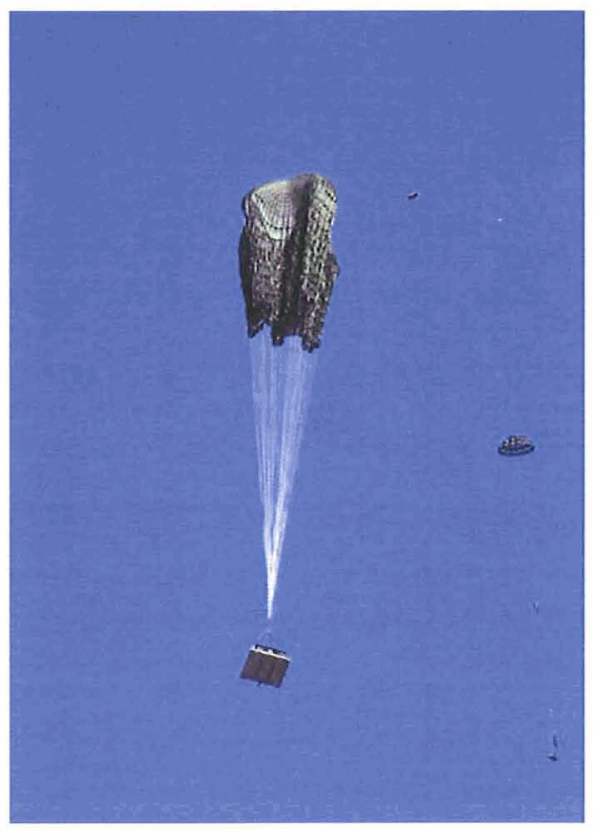

Figure 6. Canopy infold on test 4

\section{H. Failure Analysis and Findings}

The analysis of the first three drop test failures identified the need for design changes to prevent skirt inversion and to ensure parachute inflation to full open.

\section{Skirt Inversion}

The video analysis of the three drop tests revealed an important finding: bag strip occurs at a high angle of attack. When a heavy airdrop load is extracted, the recovery parachute deployment bag is pulled from the load as it leaves the ramp. The unrestrained load falls due to gravity and is well below the ramp level at parachute line stretch. The extraction parachute stays at or above ramp level, so the recovery parachute deployment bag is at a considerable 
angle of attack as the parachute is being deployed, as shown in Fig. 7, which is not typical for large parachutes used in other applications such as vehicle recovery.

The crossflow due to the angle of attack blows the canopy fabric on the windward side toward the opposite side (infolding) and under the skirt band. The skirt band inflates outside the main canopy, closing the air inlet at the skirt.

Once the skirt inlet is closed, the canopy cannot inflate properly because no air can be ingested. Even if the skirt inlet is only partially closed, inflation will be very sluggish and may stop if the inward pressure on skirt fabric can overcome the outward pressure at the inflating vent. Traditional pocket bands are ineffective in preventing this problem, because they are designed to function at small angles of attack. Once infolds have formed, pocket bands cannot develop enough outward force to overcome the pressure acting on the large infolded canopy area near the skirt. In addition, if the huge expanse of skirt material is not controlled during canopy deployment, the material on the windward side

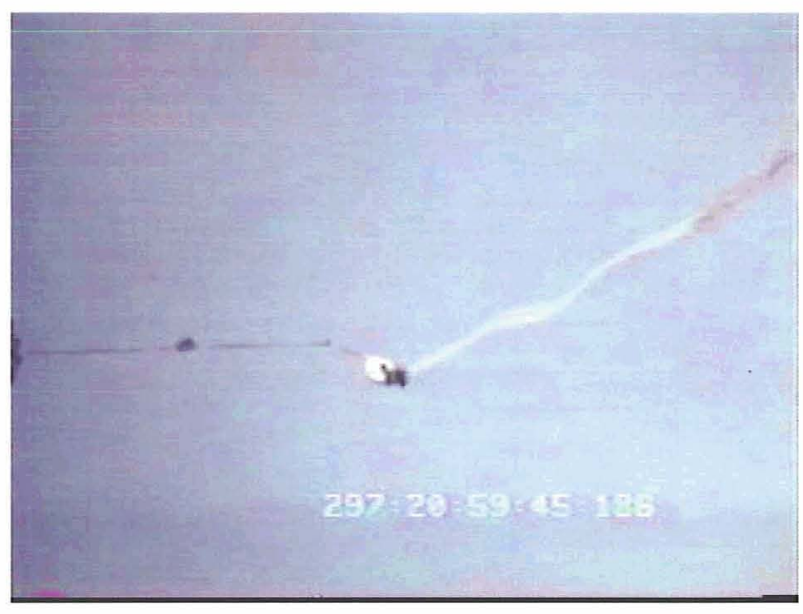

Figure 7. Large angle of attack at bag strip on test 2 can be blown under the skirt band on the opposite side. The result can be a "Mae West" skirt inversion, and structural failures can occur due to the very asymmetric load paths during parachute inflation in an entangled configuration.

The conclusion was reached that to prevent skirt inversion entanglement, the skirt needs to be controlled and kept at a small diameter until the canopy vent is pressurized, which occurs about two seconds after line stretch. The G-11 parachute uses a reefing line with a two second reefing cutter, indicating the G-11 may have experienced similar deployment problems during their development. The reefing line for a G-11 parachute uses a reefing line length of two inches per gore. Therefore, a fix was incorporated into the X-38 parachute to add a reefing line that has a length of 2.5 inches per gore and a two second reefing cutter. Drop test 4 successfully demonstrated that the addition of the reefing line prevented the occurrence of the skirt inversion and its associated damage.

\section{Failure to inflate to full open}

While the skirt inversion did not occur on drop test 4, large infolds at the skirt still provided enough blockage to prevent inflation of the parachute. At this point it became clear that a vent porosity that works well for a normal parachute application, such as vehicle recovery, would not be adequate for the 500-foot LVAD application. The large amount of skirt blockage was preventing most of the normal amount of air from being captured inside of the canopy. It became clear that to pressurize the canopy vent area with even a small amount of inflow at the skirt, the vent would have to be made completely imporous. A low porosity liner was inserted in the vent region of all three parachutes. The liner extended down to the top of the uppermost large ring of the ringslot section of the canopy, where it could be attached to a lateral reinforcement that already existed at that location. A larger liner was desired but could not be incorporated in the short time available to finish the modifications because no other lateral reinforcements existed farther down the canopy to provide attachments for the liner. Some significant packing changes were also made at this point. The canopy skirt was spread open at the canopy compartment mouth to maximize inward airflow, and additional canopy ties were added to keep the parachute stretched out.

A single parachute modified to include a liner was flown in the fifth test. A cluster of 3 of the parachutes, each modified with a liner, was deployed in the fifth test. All parachutes that were modified to include the short reefing line and liner fully inflated. There was no evidence of skirt inversion or its associated damage on any of the parachutes. This once again showed that the temporary reefing line was preventing skirt inversion as intended and provided evidence that the reduced porosity in the vent area due to the presence of the liner improved the inflation performance.

\section{Cause of high angle of attack deployment}

The cause of the high angle of attack at parachute deployment for the 500-ft LVAD environment was attributed above to the pallet dropping after exiting the ramp and the extraction parachute remaining at its original level. This is only partially correct. The angle of attack induced by the difference in altitudes between the extraction parachute and pallet is only about 8 degrees at bag strip, probably not enough to cause all of the problems observed. In close 
proximity to the aircraft, the downwash in the aircraft wake increases the induced angle of attack by some unknown amount. Again, this is probably not enough to provide the overpowering inflation and skirt inversion problems.

A frame-by-frame study of the video tapes of the pallet and deploying parachute was initiated to investigate the $500-\mathrm{ft}$ LVAD parachute deployment problems. Although the results are somewhat speculative at this point, they are present here for consideration. The videos show that after the pallet leaves the aircraft ramp and extraction line load is transferred from the pallet to the parachute deployment bag, significant dynamics are induced into the deploying riser and suspension lines. Some transverse waves of significant amplitude are generated by the load transfer and the dropping pallet that travel between the pallet and the deployment bag through the riser and suspension lines. When a wave reflects off the deployment bag with a downward amplitude, a large (greater than 45 degrees) local angle can develop. This large angle causes significant cross-flow drag on the risers and suspension lines. The wave motion probably also creates large inertial loads on the material exiting the deployment bag. The combination of the aerodynamic and inertial loads likely overpowers the fairly weak line ties used on this type of parachute. A type of line sail results that only makes the situation worse. A more careful study of this phenomenon is obviously needed. A wide angle view of the deploying line motion is shown in Fig. 8, and a close up view is shown in Fig. 9.

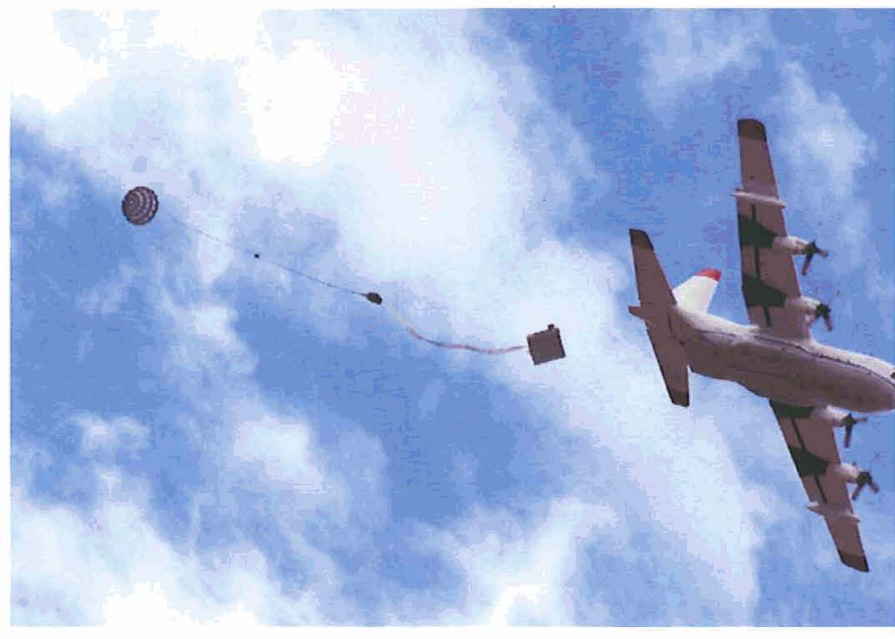

Figure 8. Deploying line motion on test 5.

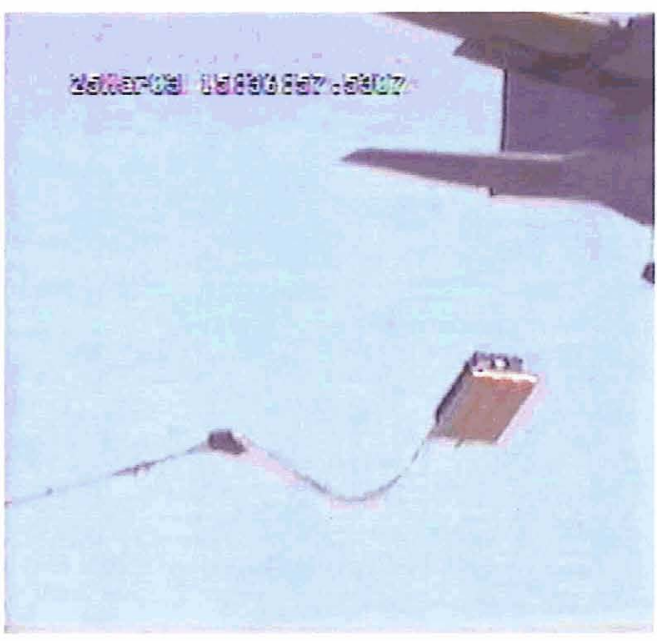

Figure 9. Deploying line motion on test 4

\section{Implications for large parachute design}

The deployment environment is very severe for large parachutes using standard heavy airdrop procedures like the 500-ft LVAD project does. The severity does not include the usual design parameters that make large parachute design challenging, like high Mach number, high dynamic pressure, or high loads. Deploying large parachutes in the standard heavy airdrop mode is difficult because of the high angle of attack at bag strip that causes skirt inversion and canopy inflation problems. Surprisingly, this set of problems does not seem to have been studied in the literature ${ }^{7,8}$, at least not directly. The literature does contain a prevailing opinion that "large parachutes must have a lower porosity than small parachutes to perform correctly." Although some of the reasons for this opinion are probably caused only by the different applications for large and small parachutes, the heavy airdrop deployment problems probably provide another significant set of contributions. Most large parachutes, regardless of their application, must be tested using heavy airdrop aircraft and loads using approved procedures. The parachutes must perform properly in the test environment in addition to their operational environment. Most large parachutes are reefed, so the skirt inversion problem should not be important. However, the airdrop test environment would certainly drive large parachute designs to lower porosities. The large SRB parachutes ${ }^{9}$ and Sandia weapon parachutes ${ }^{10}$ were not tested using airdrop methods, and they performed adequately at higher porosities, just like small wind tunnel models did. 


\section{Conclusions}

Several important lessons were learned in the drop test program. First, the cause of the parachute damage and poor inflation was due to a high angle attack at parachute deployment induced by the conventional airdrop extraction method. This problem gets worse with increasing parachute size because it takes longer to deploy the parachute, and during that time the load falls farther. That could be why G-11 parachutes require temporary reefing and G12 parachutes do not. Second, the skirt inversion and associated damage can be prevented by implementing temporary reefing. The reefing line length and reefed-time delay selected worked, but more testing is suggested to optimize the configuration. Third, skirt blockage can be overcome by making the top or vent region of the parachute imporous. Again, the configuration tested was not optimized, but complete inflation to full open was achieved. The liner needs to extend farther down from the vent. Obviously, any operational parachutes would be built with a solid top, which would be simpler and cheaper than the original design proposed. The liner technique, however, does provide a way of experimentally determining how large the solid top should be.

\section{Acknowledgments}

The authors thank the following individuals for their contributions to this test program: Brian Anderson, the NASA X-38 Program Manager, and Major Jonathan Cash and Jay Connors of Natick for supporting this cooperative drop test program; Bruce Rutledge of USA for his leadership in the design and manufacturing of the parachutes; Pete Cuthbert for his valuable computer modeling of the extraction method; Paul Royall and Dwayne Smith of Lockheed Martin-Houston for providing instrumentation expertise; and Ray Schultz and Becky Brocato of Yuma Proving Ground for their tireless assistance in making this rapid test series possible.

\section{References}

\footnotetext{
${ }^{1}$ Machin, R., Stein, J., and Muratore, J., "An Overview of the X-38 Prototype Crew Return Vehicle Development and Test Program", AIAA-99-1703, $15^{\text {th }}$ CEAS/AIAA Aerodynamic Decelerator Systems Conference, June 1999

${ }^{2}$ Rutledge, B., Hillebrandt, D., Heindel, K., and Wolf, D., "A Textile Vent Hoop Replacement for Parachute Vent Lines", AIAA-2001-2041, 16 ${ }^{\text {th }}$ CEAS/AIAA Aerodynamic Decelerator Systems Conference, May 21-24, 2001.

${ }^{3}$ Mullins, W. M., Reynolds, D. T., Lindh, K. G. and Bottorff, M. R., "Investigation of Prediction Methods for the Loads and Stresses of Apollo Type Spacecraft Parachutes - Volume II - Stresses," Northrop Corporation Report NVR-6432, Newbury Park, California, June 1970.

${ }^{4}$ Muratore, J. and Iacomini, C., "Parafoil Flight Test of X-38 Prototype Crew Return Vehicle Yields Improved Instrumentation and Techniques", ITEA Journal of Test and Evaluation, pages 19-24, June/July 1998

${ }^{5}$ Cuthbert, P., "A Software Simulation of Cargo Drop Tests", AlAA-2003-2132, $17^{\text {th }}$ CEAS/AIAA Aerodynamic Decelerator Systems Conference, May 2005

${ }^{6}$ Machin, R., Fitzgerald, S., Royall, P., and Walcer, M., "Technique for Measuring Parafoil Deployment and Steady State Loads in the Dispersion Risers and Leading Edge Reinforcement", AIAA-99-1733, $15^{\text {th }}$ CEAS/AIAA Aerodynamic Decelerator Systems Conference, June 1999

${ }^{7}$ Ewing, E. G., Bixby, H. W. and Knacke, T. W., "Recovery Systems Design Guide," Air Force Flight Dynamics Laboratory, AFFDL-TR-78-151, Wright-Patterson Air Force Base, Ohio, December, 1978.

${ }^{8}$ Knacke, T. W., "Parachute Recovery Systems Design Manual," NWC TP 6575, Para Publishing, Santa Barbara, California, 1992.

${ }^{9}$ Runkle, R. E. and Wolf, D. F., "Space Shuttle Solid Rocket Booster Lightweight Recovery System," $A I A A 13^{\text {th }} A I A A$ Aerodynamic Decelerator Systems Technology Conference, AIAA 95-1594, Clearwater, Florida, May 15-18, 1995, pp 379-386.

${ }^{10}$ Johnson, D. W., and Peterson, C. W., "High-Speed, Low-Altitude Delivery Using a Single Large Parachute," AIAA $8^{\text {th }}$ Aerodynamic Decelerator and Balloon Technology Conference, AIAA 84-0803, Hyannis, Massachusetts, April 2-4, 1984.
} 